\title{
CORRIGENDUM
}

\section{Common SNPs explain some of the variation in the personality dimensions of neuroticism and extraversion}

AAE Vinkhuyzen, NL Pedersen, J Yang, SH Lee, PKE Magnusson, WG lacono, M McGue, PAF Madden, AC Heath, M Luciano, A Payton, M Horan, W Ollier, N Pendleton, IJ Deary, GW Montgomery, NG Martin, PM Visscher and NR Wray

Translational Psychiatry (2012) 2, e125; doi:10.1038/tp.2012.49; published online 29 May 2012

Correction to: Translational Psychiatry (2012) 2, e102; doi:10.1038/tp.2012.27; published online 17 April 2012

Following the online publication of this article, the authors noted that the affiliation for Dr A Payton and W Ollier was incorrect. The corrected affiliation is Centre for Integrated Genomic Medical Research, University of Manchester, Manchester, UK. 